\title{
A formalization of one of the main claims of "Overlap of vitamin A and vitamin D target genes with CAKUT-related processes" by Ozisik et al. $2021^{1}$
}

Friederike Ehrhart ${ }^{\mathrm{a}, *}$ and Chris T. Evelo ${ }^{\mathrm{b}, \mathrm{c}}$

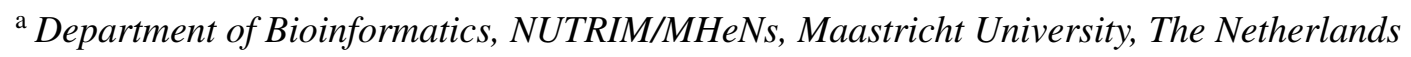

E-mail: friederike.ehrhart@maastrichtuniversity.nl; ORCID: https://orcid.org/0000-0002-7770-620X

${ }^{\mathrm{b}}$ Department of Bioinformatics, NUTRIM, Maastricht University, The Netherlands

${ }^{\mathrm{c}}$ Maastricht Center for Systems Biology (MaCSBio), Maastricht University, The Netherlands

E-mail: chris.evelo@maastrichtuniversity.nl; ORCID: https://orcid.org/0000-0002-5301-3142

Editor: Cristina-Iulia Bucur (https://orcid.org/0000-0002-7114-6459)

Review comments from: Tobias Kuhn (https://orcid.org/0000-0002-1267-0234); Cristina-Iulia Bucur (https://orcid.org/0000-0002-7114-6459)

\begin{abstract}
In a previous paper that we co-authored (Ozisik et al. 2021) we showed that in some cases Vitamin A and Vitamin D receptor binding sites are present in genes associated with Congenital Anomalies of the Kidney and Urinary Tract (CAKUT). From that finding we derived the statement that sometimes Vitamin A targets are the same as genes associated with CAKUT. We present here a formalization of that claim, stating that all things of class "genes associated with CAKUT" sometimes have a relation of type "is same as" to a thing of class "targets of vitamin A".
\end{abstract}

Keywords: Genes associated with CAKUT, targets of vitamin A

\section{Introduction}

We present here a formalization of the main scientific claim from Ozisik et al. [2] by using a semantic template called the super-pattern [1].

\footnotetext{
${ }^{1}$ As RDF/nanopublication: http://purl.org/np/RAyg4UgIVovBGia-hk4qEuRzOq14fcOlYAclC6YGQaVYU

*Corresponding author. E-mail: friederike.ehrhart@ maastrichtuniversity.nl.
} 


\section{Formalization}

Our formalization looks as follows:

$\begin{array}{ll}\text { CONTEXT-CLASS (“in the context of all...”): } & \text { (universal context) } \\ \text { SUBJECT-CLASS ("things of type...”): } & \begin{array}{l}\text { genes associated with CAKUT } \\ \text { Sometimes }\end{array} \\ \text { QUALIFIER: } & \text { is same as } \\ \text { RELATION-TYPE ("have a relation of type...”): } & \text { targets of vitamin A } \\ \text { OBJECT-CLASS ("to things of type...”): } & \end{array}$

In the context class we use the class "universal context" from SuperPattern ontology. In the subject class, we use the class "genes associated with CAKUT" (Q109406970) from Wikidata. In the object class we use the class "targets of vitamin A" (Q109406949) from Wikidata.

\section{RDF code}

This is our formalization as a nanopublication in TriG format:

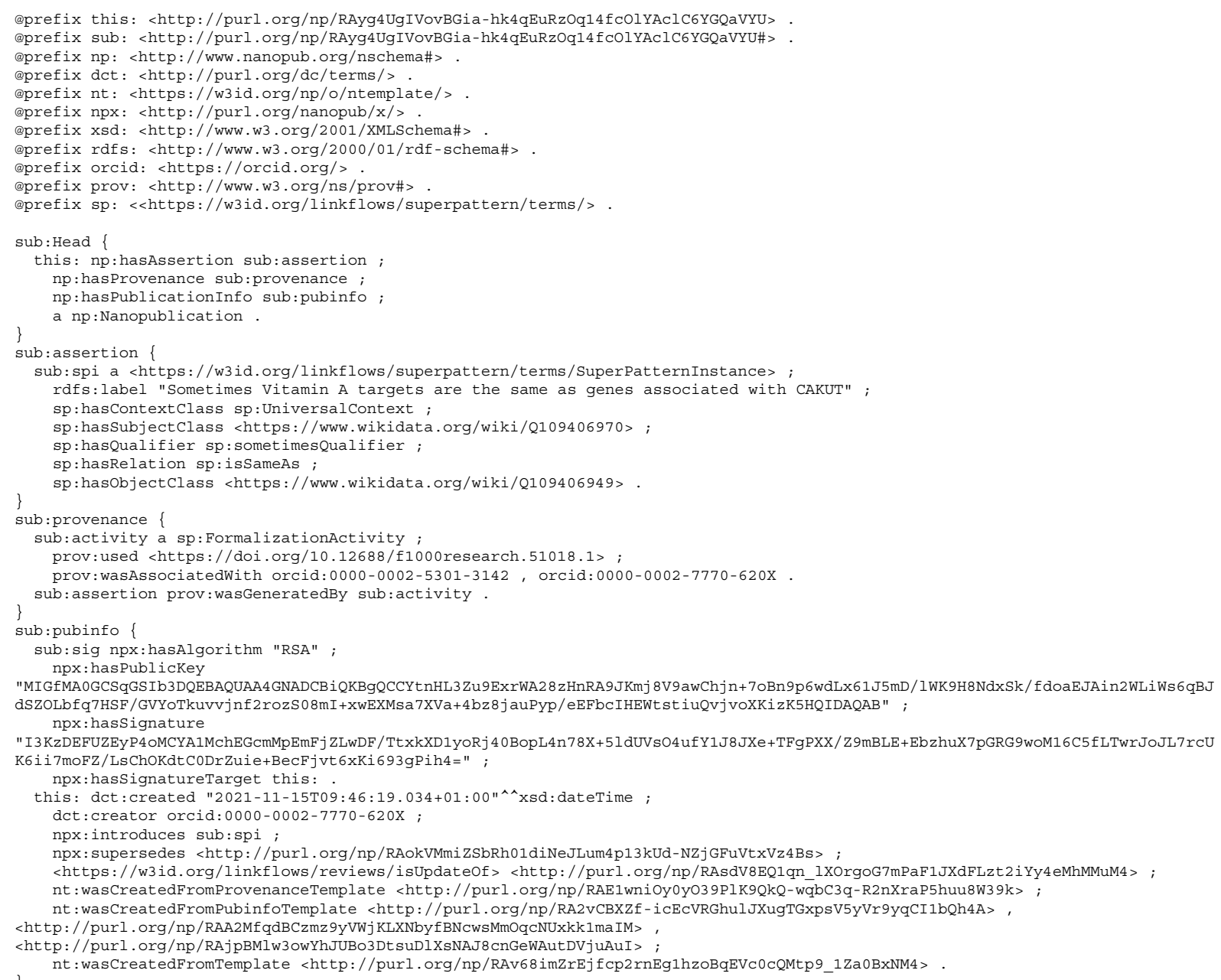




\section{Funding}

FE and CEs work is supported by the funding from the European Union's Horizon 2020 research and innovation programme under the EJP RD COFUND-EJP $\mathrm{N}^{\circ} 825575$.

\section{References}

[1] C.I. Bucur, T. Kuhn, D. Ceolin and J. van Ossenbruggen, Expressing high-level scientific claims with formal semantics, in: Proceedings of the 11th Knowledge Capture Conference, 2021. doi:10.1145/3460210.3493561.

[2] O. Ozisik, F. Ehrhart, C.T. Evelo et al., Overlap of vitamin A and vitamin D target genes with CAKUT-related processes [version 1, peer review: 2 approved with reservations]. F1000Research 10 (2021), 395. doi:10.12688/f1000research. 51018.1. 